\title{
Club cell protein 16 in sera from trauma patients modulates neutrophil migration and functionality via CXCR1 and CXCR2
}

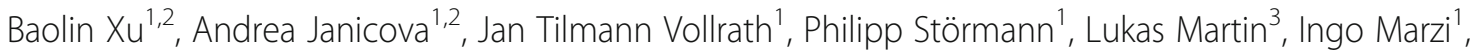
Sebastian Wutzler ${ }^{4}$, Frank Hildebrand ${ }^{5}$, Sabrina Ehnert ${ }^{6+}$ and Borna Relja ${ }^{1,2^{*+}}$ (D)

\begin{abstract}
Background: Club Cell protein (CC)16 correlates with lung injury and respiratory complications, which are in part triggered by polymorphonuclear leukocytes (PMNL) in severely traumatized patients (TP). CC16 exerts antiinflammatory and immunosuppressive effects, however, its influence on PMNL functions after trauma is unknown. Here, we evaluated whether CC16 present in sera from TP could modify the biological functions of PMNL.

Methods: Sera from 16 severely injured TP without pneumonia (no $P, n=8$ ) or with pneumonia $(P, n=8)$ were collected at admission to emergency department (ED) and 1 day prior pneumonia and pre-incubated with or without anti-CC16 antibody for CC16 neutralization. Samples from the equal post-injury days in the corresponding no $P$ group were used. Neutrophils were isolated from healthy volunteers $(H V, n=5)$ and incubated with $20 \%$ of the serum medium from TP, respectively. In PMNL, CD62L, CD11b/CD18 and CD31 expression, migratory capacity, phagocytosis rate, oxidative burst and apoptosis were investigated. In isolated PMNL, CXCR1 and CXCR2 were neutralized before stimulation with CC16, and oxidative burst, phagocytosis and apoptosis were analyzed in neutrophils and their subsets.
\end{abstract}

Results: Serum from the P group enhanced significantly PMNL migration compared to no P group, while CC16neutralization further increased the migratory rate of PMNL in both groups. CC16-neutralization increased significantly the expression of $C D 62 \mathrm{~L}$ in the $\mathrm{P}$ group at ED. Oxidative burst was significantly increased in the $\mathrm{P}$ group vs. no P during the study period. CC16 seemed to have no influence on oxidative burst and phagocytosis in TP. However, in a more controlled study design, CC16 induced a significant increase of oxidative burst and a decrease of apoptosis of $\mathrm{CD}_{16}{ }^{+}$granulocytes. These effects were markedly observed in mature CD16 ${ }^{\text {bright }} \mathrm{CD} 62 \mathrm{~L}^{\text {bright }}$ and immune suppressive $\mathrm{CD} 16^{\text {bright }}{ }^{\mathrm{CD}} 62 \mathrm{~L}^{\text {dim }}$ neutrophils. In mature subset, $\mathrm{CXCR} 1$ and $\mathrm{CXCR2}$ neutralization diminished CC16-induced effects.

Conclusions: CC16 in sera from multiply traumatized patients, notably of those with pneumonia, has significant effects on PMNL. The results suggest an association of CC16 with CXCR1 and CXCR2. Our data suggest that CC16 reduces the migratory capacity of PMNL and thus modulates their function in patients with respiratory complications after trauma.

Keywords: Trauma, Pneumonia, Neutrophils, Migration, ROS, Phagocytosis, Apoptosis

\footnotetext{
* Correspondence: info@bornarelja.com

${ }^{\dagger}$ Sabrina Ehnert and Borna Relja contributed equally to this work.

'Department of Trauma, Hand and Reconstructive Surgery, University

Hospital Frankfurt, Goethe University, Frankfurt, Germany

${ }^{2}$ Department of Radiology and Nuclear Medicine, Experimental Radiology,

Otto von Guericke University Magdeburg, Magdeburg, Germany

Full list of author information is available at the end of the article
}

(c) The Author(s). 2019 Open Access This article is distributed under the terms of the Creative Commons Attribution 4.0 International License (http://creativecommons.org/licenses/by/4.0/), which permits unrestricted use, distribution, and

reproduction in any medium, provided you give appropriate credit to the original author(s) and the source, provide a link to the Creative Commons license, and indicate if changes were made. The Creative Commons Public Domain Dedication waiver (http://creativecommons.org/publicdomain/zero/1.0/) applies to the data made available in this article, unless otherwise stated. 


\section{Introduction}

Trauma is one of the leading causes of mortality and an important contributing factor to disability worldwide (Sadeghi-Bazargani et al. 2018; Martines et al. 2018). Adjacent to the main causes of immediate or early post-injury death e.g. massive bleeding or severe brain injuries, infectious complications such as pneumonia, sepsis or multiple organ failure (MOF) triggered by inflammatory changes provoke late mortality during the hospital stay (Liodaki et al. 2015).

Traumatic injury initiates the release of endogenous damage-associated molecular patterns such as high mobility group box 1 or interleukin (IL)-1 (Eigenbrod et al. 2008; Scaffidi et al. 2002), as well as pathogen-associated molecular pattern such as lipopolysaccharide or heptose1,7-bisphosphate (Wang et al. 2018; Gaudet et al. 2015) causing a proinflammatory response. This reaction is closely associated with an excessive release of further cytokines such as IL-8, tumor necrosis factor (TNF)- $\alpha$, IL6, and IL-1 $\beta$ (Hauser and Otterbein 2018; Zhang et al. 2010a; Zhang et al. 2010b), and with the activation and recruitment of polymorphonuclear leukocytes (PMNL) with their subsequently increased immigration into tissues (Relja et al. 2013; Wagner et al. 2018). PMNL, constituting innate effector cells of the first line of defense after trauma, mediate the anti-microbial and post-injury immune response, and thereby play an important role in the progress of inflammation, contributing to the development of pneumonia (Rosales et al. 2016; Nam et al. 2018). With regard to their specific functions after trauma, a decrease of endothelial adhesion molecule Lselectin (CD62L), which initiates rolling and capturing process, and modulations of other adhesion molecules, were associated with pulmonary complications after trauma (Relja et al. 2016; Sakamaki et al. 1995; Donnelly et al. 1994; Bahra et al. 1998). Furthermore, enhanced migration of neutrophils infiltrating the lung tissue has been linked to increased pulmonary IL-8 concentration in trauma patients suffering from pneumonia or acute respiratory distress syndrome (ARDS) (Relja et al. 2016; Pallister et al. 2002; Bhatia et al. 2005). Adjacent to the changes in adhesion molecules and migratory behavior, after severe trauma, phagocytosis and oxidative burst activity of granulocytes is modulated (Sturm et al. 2017; Kanyilmaz et al. 2013; Liao et al. 2013). While several studies have shown that the migratory ability of neutrophils and production of reactive oxygen species (ROS) are strongly increased after trauma (Relja et al. 2016; Winterbourn et al. 2016; Mittal et al. 2014), a delayed apoptosis upon incubation with sera from septic patients was observed (Shen et al. 2017; Guo et al. 2006). Under the condition of acute inflammation, three neutrophil subsets can be found in the blood: cells with a conventional segmented nucleus, with a banded nucleus, and
T-cell-suppressing CD62L $\mathrm{L}^{\mathrm{dim}}$ with a high number of nuclear lobes, termed mature, banded and hypersegmented neutrophils, respectively (Silvestre-Roig et al. 2019; Pillay et al. 2012). As neutrophils age, they change their phenotype but also their functions (Nagase et al. 2002; Martin et al. 2003; Rankin 2010). Thus, although neutrophils have been generally considered as a relatively homogeneous population for several decades, evidence for their true heterogeneity is emerging.

Club cell protein (CC) 16 is a $15.8 \mathrm{kDa}$ protein secreted by club cells along the tracheobronchial tree and especially in the distal respiratory bronchioles (Komaromy and Tigyi 1988; Bernard and Lauwerys 1995). This protein increasingly appears to protect the respiratory tract against oxidative stress and inflammation, since most studies have found associations between CC16 levels and the severity of major lung insults. Lung injury correlates with increased systemic CC16 levels in severely injured trauma patients (Wutzler et al. 2011). Moreover, its secondary increase indicated the development of pneumonia after trauma (Wutzler et al. 2012; Negrin et al. 2017). Next to the clinical biomarker characteristic to predict pneumonia after trauma, there is accumulating evidence that CC16 exerts pathophysiologically relevant effects for the development of pulmonary complications, since it may reduce the production of proinflammatory cytokines (Pang et al. 2017; Pang et al. 2015). Thus, CC16 exerts anti-inflammatory functions, which have been protective also in the development of other pulmonary diseases (Laucho-Contreras et al. 2015).

Since PMNL play a center role in post-traumatic inflammation, the influence of CC16 on their biological and physiological functions during the development of pneumonia may be relevant for understanding the disease pathophysiology and improving trauma care. Therefore, we evaluated how $\mathrm{CC} 16$, which is present in sera from traumatized patients with or without pneumonia will modify the functions of PMNL.

\section{Material and methods Patients}

In this experimental trial, 16 severely injured trauma patients with a history of acute blunt or penetrating trauma and an injury severity score (ISS) $\geq 16$ and five healthy volunteers were enrolled. Individuals that were younger 18 or older 80 years of age, suffering from severe burn injury, acute myocardial infarction, cancer or chemotherapy, HIV, infectious hepatitis, acute CMV infection and/or thromboembolic events, or receiving immunosuppressive drug therapy were excluded. The ISS was calculated according to the abbreviated injury scale (AIS) upon arrival at the emergency department (ED) (Palmer et al. 2013). The patients were included consecutively according to the inclusion and exclusion criteria for 24 months. Then, out 
of 167 patients, 16 matched pairs were created. After frequency-matching of patients according to the ISS and age, patients were grouped to the cohort without pneumonia (no $\mathrm{P}, n=8)$ or with pneumonia $(P, n=8)$. The presence of pneumonia was defined by radiologic, clinical and bacteriologic findings with the presence of new pulmonary infiltrates on chest X-ray and at least one of the following criteria: positive blood culture, bronchial alveolar lavage and/or sputum culture.

\section{Blood sampling}

Immediately after admission to the ED and daily for 10 days after trauma, blood samples were withdrawn in $S$ Manovette ${ }^{\varpi}$ Z-Gel tubes (Sarstedt, Nürmbrecht, Germany). After centrifugation at $2000 \mathrm{x}$ g for $15 \mathrm{~min}$ at $4{ }^{\circ} \mathrm{C}$ the supernatants were stored at $-80^{\circ} \mathrm{C}$ for further in vitro experiments with isolated neutrophils from healthy volunteers (HV). The samples that were used are those obtained at the admission to the ED and 1 day prior diagnosis of pneumonia ( -1 day prior pneumonia) or at the same day in the corresponding group of patients without pneumonia (no P) (- 1 day prior pneumonia).

Blood samples from HV were withdrawn in heparinized tubes (Sarstedt, Nürmbrecht, Germany) and kept at room temperature until isolation of PMNL.

\section{Isolation of PMNL}

To isolate blood neutrophils the density-gradient centrifugation (Polymorphprep, density: $1.113 \pm 0.001 \mathrm{~g} / \mathrm{ml}$, Axis-Shield, Oslo, Norway) was applied according to manufacturer's instructions. Briefly, $4 \mathrm{ml}$ of Polymorphprep were covered carefully with $4 \mathrm{ml}$ heparinized blood from $\mathrm{HV}$ and centrifuged for $30 \mathrm{~min}$. Then, the PMNL cell fraction was transferred to another tube for washing procedure with phosphate buffered saline w/o $\mathrm{Ca}^{2+}$ and $\mathrm{Mg}^{2+}$ (PBS, Invitrogen). The number of PMNL as well as their viability were determined by the trypan blue exclusion assay. The cells were cultured in RPMI 1640 medium (Seromed, Berlin, Germany; polypropylene tube, BD Bioscience, Franklin Lakes, NJ, USA) supplemented with $10 \%$ heat-inactivated fetal calf serum (FCS), $100 \mathrm{IU} /$ $\mathrm{mL}$ penicillin, and $100 \mu \mathrm{g} / \mathrm{mL}$ streptomycin (Gibco, Karlsruhe, Germany) and $20 \mathrm{mM}$ HEPES buffer (Sigma, Deisenhofen, Germany). Only cell cultures with a purity of > 95\% were utilized for experimental use. For the analysis of the effects of sera obtained from TP, PMNL were cultured in media containing $20 \%$ of TP serum as described below.

\section{Cell stimulation}

In vitro experiments with isolated neutrophils from healthy volunteers (HV) included the incubation of cells either with IL-8 (10 ng/ml, R\&D Systems, Wiesbaden), the recombinant human CC16 (CC16_I: $100 \mathrm{ng} / \mathrm{ml}, \mathrm{CC} 16$ II: $33.33 \mathrm{ng}$ / $\mathrm{ml}$ and CC16_III: $1 \mathrm{ng} / \mathrm{ml}$, respectively, R\&D Systems) or with sera from TP that were obtained at the admission to the ED or 1 day prior to diagnosis of pneumonia ( -1 day prior pneumonia) or at the same day in the corresponding group of patients without pneumonia (no P) ( -1 day prior pneumonia). The serum: media ratio was 1: 5 . Furthermore, sera from TP were either pre-incubated with or without anti-CC16-antibody for CC16-neutralization $(10 \mathrm{ng} / \mathrm{ml}$, human uteroglobin affinity purified $A b, R \& D$ Systems). Additional in vitro analyses included the neutralization of CXCR1 or CXCR2, respectively, with antibodies $(1 \mu \mathrm{g} / \mathrm{ml}$, Human CXCR1/IL-8 RA Antibody and Human CXCR2/ IL-8 RB Antibody; R\&D Systems) or with the corresponding isotype controls $(1 \mu \mathrm{g} / \mathrm{ml}$, Mouse IgG2A Isotype Control; R\&D Systems) for 1 hour prior stimulation of the cells with CC16 (100 ng/ml) for another hour.

\section{Migration assay}

Migration capacity of isolated PMNL was examined using modified Transwell 24-well chambers (Corning, New York, USA) with $3-\mu$ m pores. Before the evaluation of the migratory rate of neutrophils, cell number was equalized to $1 \times 10^{6}$ vital cells $/ \mathrm{ml}$. Subsequently, $100 \mu \mathrm{l}$ of the cell suspension were placed in the upper chamber. The lower chamber contained $500 \mu$ l RPMI 1640 with supplements and either IL-8 (10 ng/ml, R\&D Systems), the recombinant human CC16 (CC16_I: $100 \mathrm{ng} / \mathrm{ml}$, CC16_II: $33.33 \mathrm{ng} / \mathrm{ml}$ and CC16_III: $1 \mathrm{ng} / \mathrm{ml}$, respectively, R\&D Systems) or $20 \%$ serum obtained from TP. The sera from TP were either pre-incubated with or without anti-CC16-antibody for CC16-neutralization (10 ng/ml, human uteroglobin affinity purified Ab, R\&D Systems). After incubation for $3 \mathrm{~h}$ at $37^{\circ} \mathrm{C}$ and $5 \% \mathrm{CO}_{2}$, the upper transwell chamber was removed and cells migrating to the lower chamber were collected and counted after their staining with Türks-solution (1: 1, Merck). The number of cells migrating into the lower compartment was quantified. The migratory capacity of control (ctrl) cells that were incubated without serum in the lower compartment was set as $100 \%$.

\section{Measurement of cell surface receptor expression by flow cytometry}

Isolated PMNL $\left(2 \times 10^{6}\right.$ cells $\left./ \mathrm{ml}\right)$ were transferred in $250 \mu \mathrm{l}$ RPMI 1640 with supplements as described above including 20\% serum from TP. Control samples were incubated in medium containing supplements without sera, and as an additional control IL- 8 was applied to the medium. The samples were incubated at $37^{\circ} \mathrm{C}$ and $5 \% \mathrm{CO}_{2}$ for 2 hours. Subsequently, the samples were centrifuged at $2100 \mathrm{x}$ g for $15 \mathrm{~min}$, the supernatant was removed and the cells were transferred into polystyrene FACS tubes. Then, the samples were incubated with mouse anti-human CD62L APC (clone: DREG-56), mouse anti-human CD31 (clone: WM59) and mouse 
anti-human CD11b/Mac-1 PE (clone: ICRF44, all BD Pharmingen) antibodies for $30 \mathrm{~min}$. After subsequent washing procedure with $4 \mathrm{ml}$ PBS supplemented with $0.5 \%$ bovine serum albumin (FACS buffer) at $400 \mathrm{x}$ g for $5 \mathrm{~min}$, the supernatants were removed and the cells were resuspended in $200 \mu \mathrm{l}$ FACS buffer. Flow cytometric analyses of cell surface markers on a minimum of 20.000 cells was performed using BD FACS Canto $2^{\mathrm{ru}}$ and FACD DIVA ${ }^{\mathrm{T}}$ software (BD). The neutrophils were gated by the corresponding forward and side scatter scan (FSC and SSC) as shown in Fig. 2 a. Mean fluorescence units (MFU) were detected.

\section{Oxidative burst}

Isolated PMNL $\left(2 \times 10^{6}\right.$ cells $\left./ \mathrm{ml}\right)$ were cultured as described above with or without $20 \%$ sera and with or without CC16-neutralization, respectively, or with IL-8. Control samples were incubated in culture medium. The samples were incubated at $37{ }^{\circ} \mathrm{C}$ and $5 \% \mathrm{CO}_{2}$ for $2 \mathrm{~h}$ and subsequently centrifuged at $2100 \mathrm{x}$ g for $15 \mathrm{~min}$. Cell pellet was resuspended in culture medium $(1 \mathrm{ml})$ with supplements and $100 \mu \mathrm{l}$ of the cell suspension were transferred into polystyrene FACS tubes.

In a second in vitro experiment, isolated neutrophils were incubated with anti-CXCR1 or CXCR-2 antibodies for the neutralization of CXCR1 or CXCR2, respectively, or with the corresponding isotype controls $(1 \mu \mathrm{g} / \mathrm{ml})$ for 1 hour prior to the stimulation of the cells with CC16 $(100 \mathrm{ng} / \mathrm{ml})$ for another hour. Then, the samples were washed with FACS buffer and incubated with mouse antihuman CD62L PE-Cy7 (clone: DREG-56, BioLegend) and mouse anti-human CD16 AF647 (clone: 3G8, BD Pharmingen) antibodies for $30 \mathrm{~min}$. After subsequent washing procedure with FACS buffer as described above, the supernatants were removed and cells were resuspended in $100 \mu \mathrm{l}$ FACS buffer.

In both in vitro experiments, $20 \mu \mathrm{l} C M-\mathrm{H}_{2}$ DCFDA $\left(\mathrm{CM}-\mathrm{H}_{2} \mathrm{DCFDA}\right.$, General Oxidative Stress Indicator Kit, Invitrogen, Darmstadt, Germany) were added to each sample and the samples were incubated for $30 \mathrm{~min}$ at $37^{\circ} \mathrm{C}$ and $5 \% \mathrm{CO}_{2}$. Thereafter, $400 \mu \mathrm{l}$ of the culture medium were added to each sample. After 1 hour at $37^{\circ} \mathrm{C}$ and $5 \% \mathrm{CO}_{2}$, cells were washed with FACS buffer, the supernatants were removed, and cells were resuspended in $200 \mu \mathrm{l}$ FACS buffer for subsequent flow cytometric analyses as described above. The gating was performed as shown in Fig. 3 a. According to manufacturer's protocol, the negative populations were set according to the $\mathrm{CD} 16^{+}$ ROS-negative population. Then, the percentage of positive cells for oxidative stress and the MFU were determined.

\section{Phagocytosis}

Isolated neutrophils were cultured as described above. Instead of applying the $\mathrm{CM}-\mathrm{H}_{2} \mathrm{DCFDA}$, here, $\mathrm{pHrodo}{ }^{\text {mat }}$
Red Staphylococcus aureus Bioparticles ${ }^{\circ}$ Conjugate for Phagocytosis (Invitrogen, Darmstadt) were used. $100 \mu \mathrm{l}$ $\mathrm{pHrodo}^{\text {tw }}$ Red Staphylococcus aureus Bioparticles ${ }^{\bullet}$ were added to each sample and the samples were incubated for 1 hour at $37^{\circ} \mathrm{C}$ and $5 \% \mathrm{CO}_{2}$. Thereafter, cells were washed with FACS buffer, the supernatants were removed, and cells were resuspended in $200 \mu \mathrm{l}$ FACS buffer for subsequent flow cytometric analyses as described above. The gating was performed as indicated for ROS production in Fig. 3 a with the difference that phagocytosis negative $\mathrm{CD} 16^{+}$cells were applied for the settings. The percentage of positive cells for phagocytosis and the MFU were determined.

\section{Apoptosis}

Isolated neutrophils were cultured as described above. Instead of applying the $\mathrm{CM}-\mathrm{H}_{2} \mathrm{DCFDA}$, here, Annexin V: FITC Apoptosis Detection Kit I (BD Pharmingen) was used. $5 \mu \mathrm{l}$ Annexin V-FITC and $5 \mu \mathrm{l}$ Propidiumiodid were added to $100 \mu \mathrm{l}$ of each sample and the samples were incubated for $15 \mathrm{~min}$ at room temperature. Thereafter, cells were washed with FACS buffer, the supernatants were removed, and cells were resuspended in $200 \mu \mathrm{l}$ FACS buffer for subsequent flow cytometric analyses as described above. The gating was performed as indicated for ROS production in Fig. 3 a with the difference that apoptosis negative $\mathrm{CD} 16^{+}$cells were applied for the settings. The percentage of apoptotic cells and the MFU were determined.

\section{Statistical analysis}

The statistical analyses were performed by using GraphPad Prism 6.0 software (GraphPad Software Inc. San Diego, CA). Data are given as mean \pm standard error of the mean (SEM). Kruskal-Wallis with a Dunn post-hoc test was used for comparison among different groups. A $p$ value below 0.05 was considered statistically significant.

\section{Results \\ CC16 reduces the migration of isolated neutrophils towards pro-inflammatory chemoattractants}

IL-8 administration in the lower transwell chamber induces a significant increase in PMNL migration from the upper compartment towards IL-8 compared to controls $(p<0.05$, Fig. 1). Addition of CC16 alone to the medium in the lower compartment did not markedly change migration rates compared to control. No effects regarding the dose of $\mathrm{CC} 16$ were observed either. However, the concurrent application of IL- 8 and CC16 in the lower compartment significantly decreased migration rates of PMNL compared with untreated controls and with IL-8 induced migration rates $(p<0.05$, Fig. 1$)$.

Migration of PMNL in the no $\mathrm{P}$ group was significantly lower vs. control, while the PMNL migration rate 

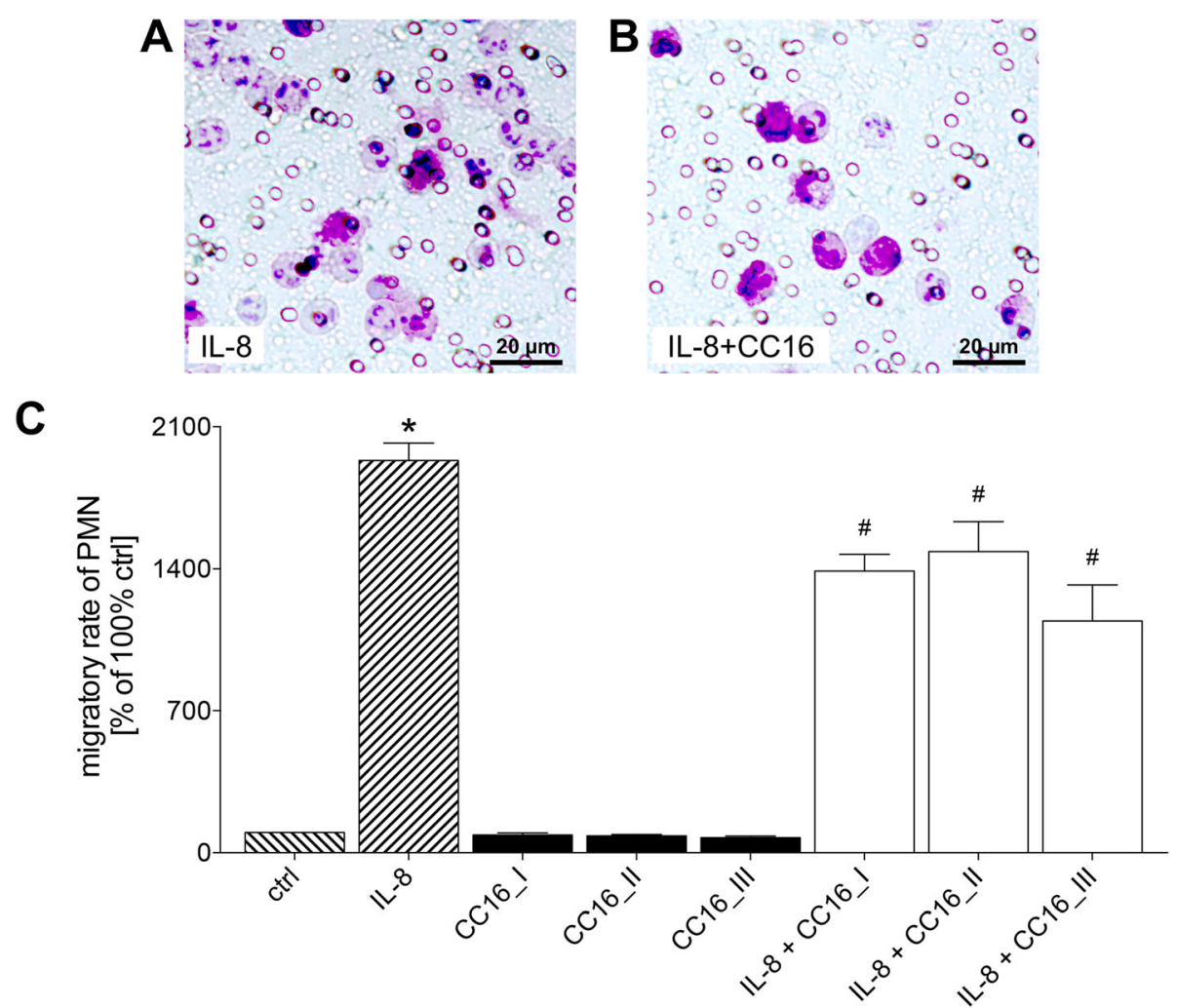

Fig. 1 CC16 reduces PMNL migration towards IL-8. Isolated PMNL that have migrated to the lower side of the membrane. a IL-8 and (b) IL-8 concurrent with CC16 as chemoattractants.(c) Migration capacity of isolated PMN towards different concentrations of CC16 (CC16_l: $100 \mathrm{ng} / \mathrm{ml}$, CC16_II: $33.33 \mathrm{ng} / \mathrm{ml}$ and CC16_III: $1 \mathrm{ng} / \mathrm{ml}$, respectively). $p<0.05:$ *: vs. all; \#: vs. Ctrl, IL-8 and CC16l, II, and III

in the P group increased significantly vs. ctrl at $\mathrm{ED}(p<$ 0.05 , Fig. 2 b). No significant changes in the PMNL migration rate in the no $\mathrm{P}$ group vs. ctrl were observed at 1 day prior pneumonia, while the PMNL migration was significantly increased in the P group vs. $\operatorname{ctrl}(p<0.05$, Fig. 2 b). Administration of sera from the $\mathrm{P}$ group to PMNL resulted in significantly higher migration rates of PMNL at ED as well as at 1 day prior pneumonia compared to the corresponding no P group $(p<0.05$, Fig. 2 b). Notably neutralization of CC16 in both groups at 1 day prior pneumonia has shown a significantly increased PMNL migration capacity compared to the corresponding samples $(p<0.05$ Fig. 2 b).

\section{CC16-reduced migratory rate of isolated neutrophils is} associated with concurrently reduced CD62L

PMNL incubation with sera from TP without or with pneumonia significantly increased the surface expression of $\mathrm{CD} 11 \mathrm{~b} / \mathrm{CD} 18$ vs. ctrl at ED as well as 1 day prior to pneumonia ( $p<0.05$, Fig. 2 c). Incubating isolated PMNL with sera from TP who developed pneumonia showed significantly decreased CD11b/CD18 expression at ED and at 1 day prior to pneumonia vs. corresponding no $\mathrm{P}$ group $(p<0.05$, Fig. 2 c). Neutralization of CC16 has shown no significant changes regarding the surface expression of CD11b/CD18 on isolated PMNL (Fig. 2 c).

Surface expression of the CD62L on isolated PMNL in the no $\mathrm{P}$ group was significantly decreased compared to ctrl at ED and 1 day prior to pneumonia $(p<0.05$, Fig. $2 \mathrm{~d})$. CD62L expression in the $P$ group was significantly increased vs. the corresponding no $\mathrm{P}$ group ( $p<0.05$, Fig. 2 d). However, there was no significant difference between the $\mathrm{P}$ group vs. ctrl. Neutralization of CC16 showed a trend to an increase in each group, however, CD62L expression was significantly increased only after CC16 neutralization in the $\mathrm{P}$ group vs. the corresponding sample at ED $(p<0.05$, Fig. 2 d).

The surface expression of CD31 on isolated PMNL did not show any significant differences among the groups (Fig. 2 e).

\section{Blockade of chemokine receptors significantly reduces} the CC16-induced oxidative stress in mature neutrophils Incubation of isolated PMNL with IL-8 did not markedly change the percentage of the oxidative burst rate vs. untreated controls (Fig. 3 b). Oxidative burst rate after incubating PMNL with samples from the $\mathrm{P}$ group was significantly increased vs. ctrl at 1 day prior to pneumonia 


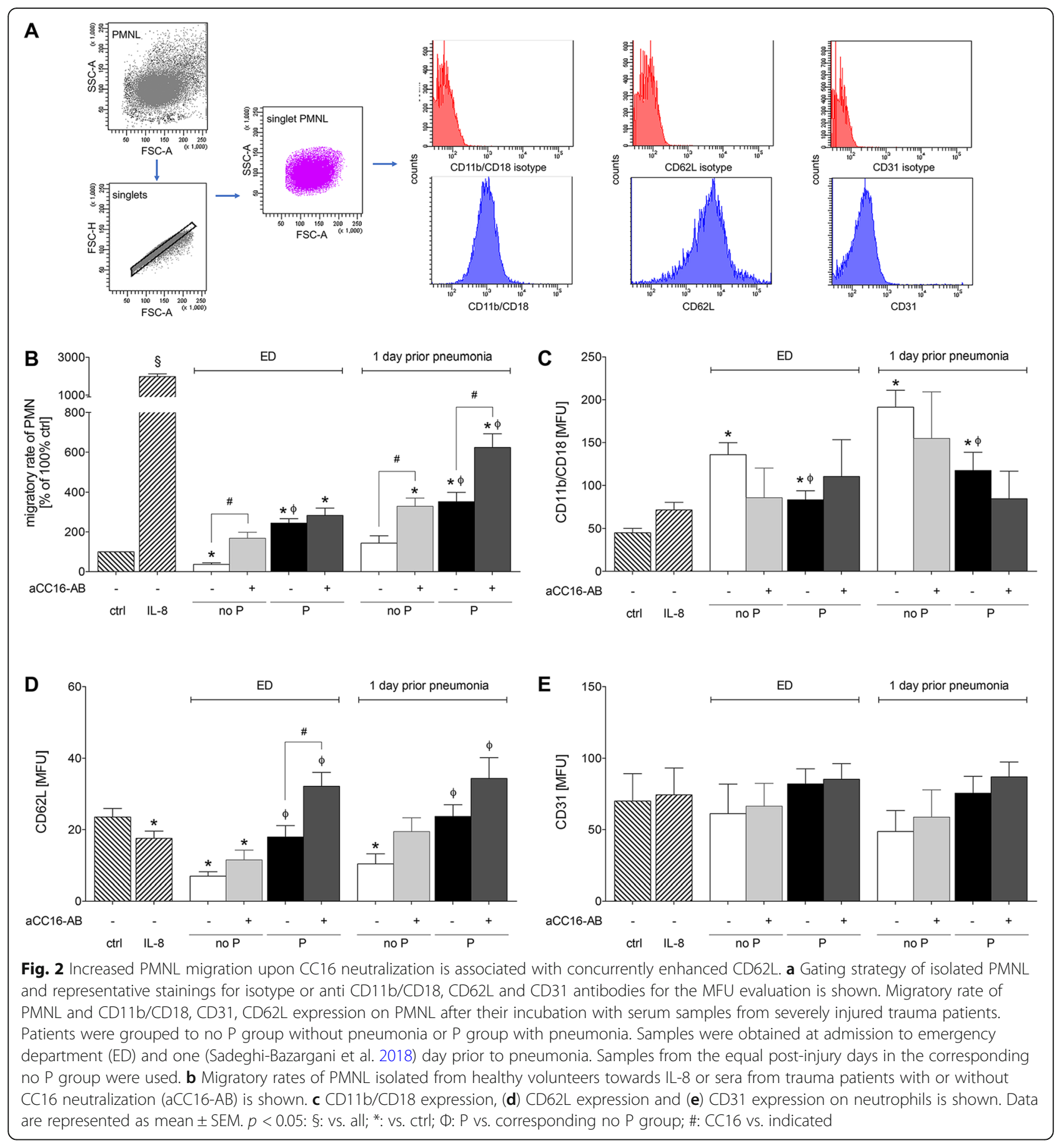

$(p<0.05$, Fig. 3 b). Administration of sera from the $\mathrm{P}$ group to PMNL has resulted in significantly increased oxidative burst rate vs. the corresponding no $\mathrm{P}$ group at ED as well as at 1 day prior to pneumonia $(p<0.05$, Fig. $3 \mathrm{~b})$. Neutralization of CC16 in the no P group has shown a significant decrease in the no $\mathrm{P}$ group vs. ctrl at ED. A significant decrease in the oxidative burst rate has been observed in the $\mathrm{P}$ group at ED and at 1 day prior to pneumonia vs. corresponding sample as well ( $p<0.05$, Fig. 3 b).

With regard to the intensity of oxidative burst, a significant induction in CC16 stimulated granulocytes vs. ctrl has been observed ( $p<0.05$, Fig. 3 c). This increase in CC16 induced oxidative burst activity persisted among granulocytes upon CXCR1 as well as after CXCR2 neutralization $(p<0.05$, Fig. 3 c). Further evaluation of 


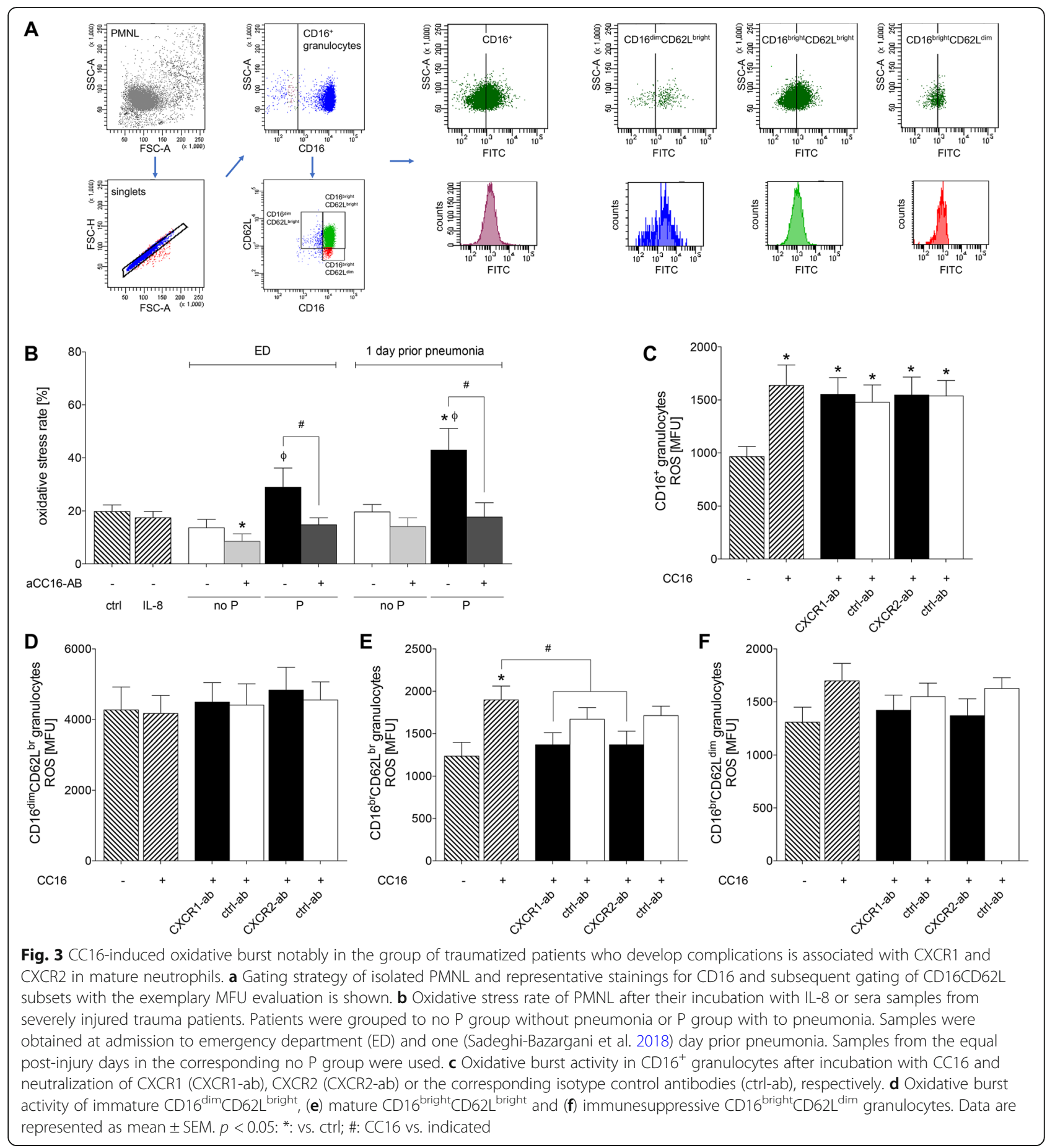

neutrophil subsets with regard to oxidative burst has shown that there were no significant changes neither in immature $\mathrm{CD} 16^{\mathrm{dim}} \mathrm{CD} 62 \mathrm{~L}^{\text {bright }}$ nor in immune suppressive $\mathrm{CD} 16^{\text {bright }}{ }^{\mathrm{CD}}$ 62 $\mathrm{L}^{\text {dim }}$ neutrophils (Fig. 3 e and f). However, oxidative burst activity has been significantly induced by $\mathrm{CC} 16$ in mature $\mathrm{CD} 16{ }^{\text {bright }} \mathrm{CD} 62 \mathrm{~L}^{\text {bright }}$ neutrophils vs. ctrl $(p<0.05$, Fig. 3 e). In this subset, CXCR1 and CXCR2 neutralization resulted in significantly diminished oxidative burst as compared with CC16 stimulated samples $(p<0.05$, Fig. 3 e).

\section{CC16 has no significant effects on phagocytosis behavior of isolated neutrophils}

The percentage of phagocytizing cells did not significantly change neither after the incubation of PMNL with IL-8 nor with sera from TP (Fig. 4 a). 


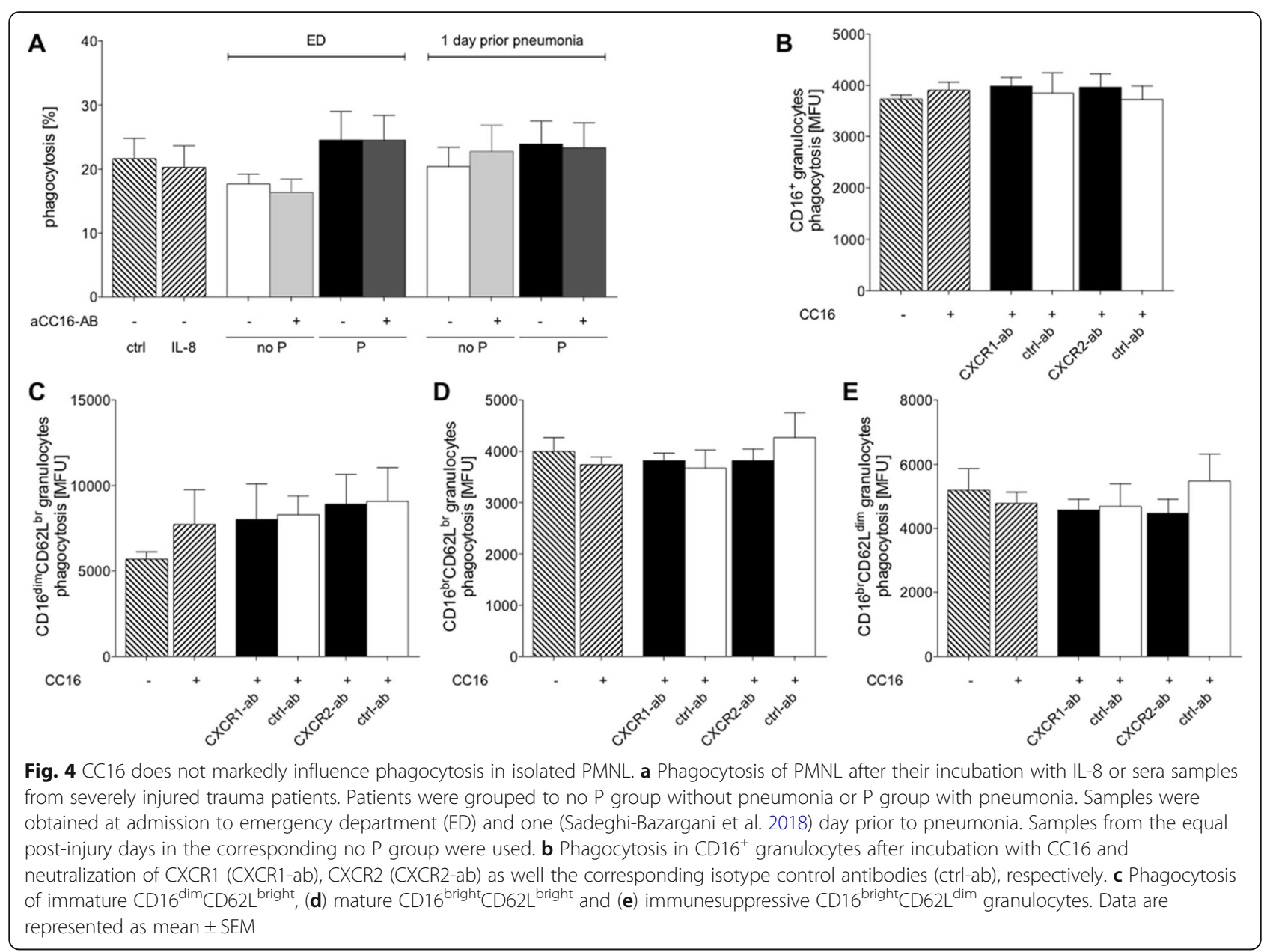

With regard to the intensity of phagocytosis, there were neither significant changes in CC16 stimulated granulocytes nor upon CXCR1 or after CXCR2 neutralization (Fig. 4 b). Further evaluation of neutrophil subsets with regard to phagocytosis has shown that there were no significant changes in immature $\mathrm{CD} 16{ }^{\mathrm{dim}} \mathrm{CD} 62 \mathrm{~L}^{\text {bright }}$, immune suppressive $\mathrm{CD} 16^{\text {bright }} \mathrm{CD} 62 \mathrm{~L}^{\text {dim }}$ and $\mathrm{CD} 16^{\text {bright }} \mathrm{CD} 62 \mathrm{~L}^{\mathrm{b}-}$ right neutrophils vs. ctrl (Fig. $4 \mathrm{~d}$ ).

\section{Blockade of chemokine receptors do not change the CC16-induced reduction of apoptosis}

Incubation of isolated PMNL with IL-8 or with sera from TP did not markedly change the percentage of the apoptosis vs. untreated controls (Fig. 5 a). Neutralization of CC16 did not show any significant differences among the groups.

Treatment of isolated granulocytes with CC16 significantly reduced apoptosis vs. untreated ctrl of $\mathrm{CD} 16^{+}$granulocytes $(p<0.05$, Fig. 5 b). Treatment of isolated granulocytes with neutralizing CXCR1 or CXCR2 antibodies diminished the $\mathrm{CC} 16$ induced reduction in apoptosis of $\mathrm{CD}_{16}{ }^{+}$granulocytes (Fig. 5 b). Treatment of isolated granulocytes with corresponding isotype control antibodies resulted in significantly reduced apoptosis after incubation with CC16 vs. $\operatorname{ctrl}(p<0.05$, Fig. 5 b). Further evaluation of neutrophil subsets with regard to apoptosis has shown no significant changes among immature $\mathrm{CD} 16^{\mathrm{dim}} \mathrm{CD} 62 \mathrm{~L}^{\text {bright }}$ neutrophils. However, treatment with $\mathrm{CC} 16$ significantly reduced apoptosis in mature $\mathrm{CD} 16^{\text {bright }} \mathrm{CD} 62 \mathrm{~L}^{\text {bright }}$ neutrophils, which has been abolished in CXCR1 as well as in CXCR2 neutralized samples (Fig. 5 d). With regard to immune suppressive CD16 ${ }^{\text {bright }} \mathrm{CD} 62 \mathrm{~L}^{\text {dim }}$ neutrophils, a significantly reduced apoptosis in $\mathrm{CC} 16$ treated cells vs. ctrl has been detected ( $p<0.05$, Fig. 5 e). In this subset, CXCR1 and CXCR2 neutralization or incubation with isotype control antibodies did not markedly change the CC16 induced reduction of apoptosis (Fig. 5 e).

\section{Discussion}

CC16 is increased in patients with pulmonary complications. Exposing isolated PMNL from HV to sera from patients with pneumonia increased migratory rates to IL-8 compared with patients without pneumonia. Furthermore, CC16-dependent decrease in IL-8 induced 


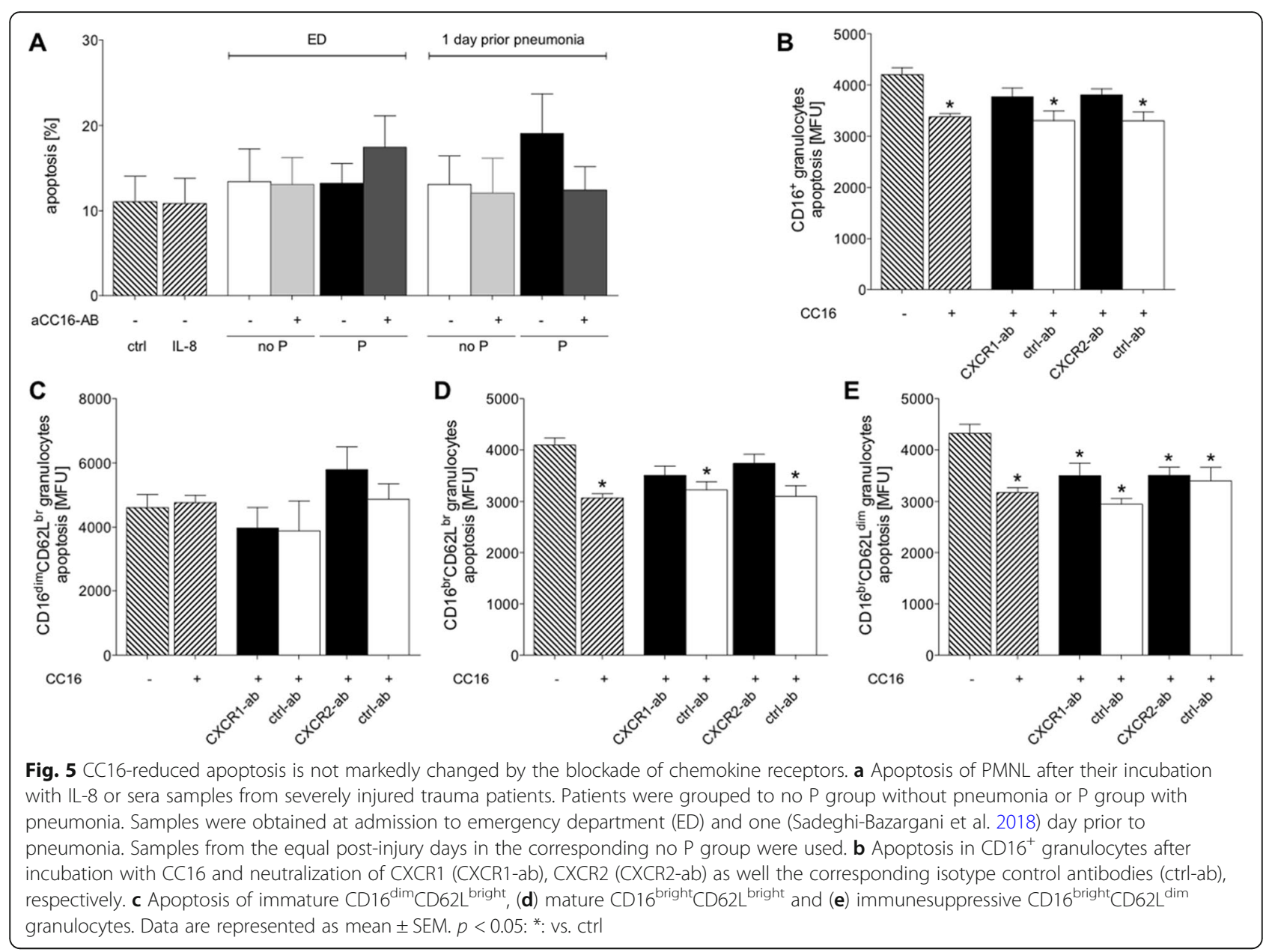

PMNL-migration emphasizes its role in neutrophil recruitment to the inflammatory site. This is in line with published data showing that CC16 reduced neutrophil migration upon stimulation with phospholipase A2 (Schrama et al. 2010). Similarly, CC16 inhibited IL-8 induced migration of equine neutrophils in a dosedependent manner (Cote et al. 2014), although we did not observe any dose-dependency. However, since we applied much lower dosages of $\mathrm{CC} 16$, possibly that the narrow range of $\mathrm{CC} 16$ concentrations may be the reason for the lack of dose-dependent differences. The underlying mechanism of CC16-dependent decrease of PMNL migration has been studied in great extent. CC16 has a high potency to inhibit the neutrophil migration toward N-formyl-methionyl-leucyl-phenylalanin (fMLP) (Johansson et al. 2009). Therefore, CC16 may modulate the PMNL migration by antagonizing fMLP receptors. Considering our results, CC16 in sera from traumatized patients may modulate neutrophil migration via CD62L and potentially via other still unknown receptors.

Along with elevated PMNL migration following treatment with TP sera and consistent with our previous findings (Relja et al. 2016), the expression of adhesion molecules CD11b/CD18 was increased, whereas the CD62L surface presentation was decreased. An inappropriate expression of adhesion molecules on PMNL and their migration may be affected by pro- and antiinflammatory mediators (Giannoudis et al. 2000). In traumatized patients with pneumonia, PMNL can downregulate the immune response by cleaving associated or essential receptors on the surface of both adaptive and innate immune cells (van den Berg et al. 2014). Less invasive transmigration of those cells has been observed following disruption of CD62L/CaM interaction by phosphorylation of CD62L at Ser 364 (Rzeniewicz et al. 2015). Apparent modulations of CD62L shedding on PMNL were related to the development of posttraumatic acute lung injury (Rainer et al. 2000). These findings are in line with the data presented in this manuscript. Weaver et al. have described that PMNL migration into injured cortex was notably increased at $24 \mathrm{~h}$ after trauma, and that this emigration could be neutralized by anti-CD11b antibody (Weaver et al. 2000). Increased expression of CD11b/CD18 on the PMNL surface may 
promote the binding to activated endothelia and, thus, enhanced penetration potency as well as emigration into surrounding tissues after trauma. Chishti et al. have shown reduced chemotaxis toward IL-8 in neutrophils from septic patients compared with healthy controls, whereby the surface expression of the chemokine receptor CXCR2 and the beta-integrin CD11b, but not CXCR1 was decreased and correlated with disease severity (Chishti et al. 2004). Involvement of CXC receptors in CC16-modulated functionality of neutrophils is in line with our findings. Similarly, enhanced neutrophilic migration after major trauma was associated with changes in the expression of their surface receptors such as upregulation of CXCR1, or down-regulation of CD11b and CD18 in patients with ARDS (Bhatia et al. 2005).

Changes in general oxidative burst are in line with previous reports showing that pulmonary complications were characterized by increased neutrophilic respiratory burst activity (Hazeldine et al. 2014; Rivkind et al. 1991). In our study, oxidative burst of $\mathrm{CD} 16^{+}$granulocytes did not change upon neutralizing CXCR1 or CXCR2 compared to CC16-induced response. In line with this data, neutrophil-like human promyelocytic cells did not show differences in ROS-production with or without transducing CXCR1 gene after incubation with IL-8 (KikuchiUeda et al. 2012). However, the effects of CC16 on oxidative burst of granulocytes were evident when analyzing notably the mature subset of neutrophils. It has been reported that the inhibition of CXCR2 reduced the superoxide production and NADPH activity in an angiotensin II or deoxycorticosterone acetate salt induced mouse hypertensive models (Wang et al. 2016). Therefore, it appears reasonable that CXC receptors may be involved in CC16 modulated ROS production predominantly in mature neutrophils after trauma. Yet, it remains to be noticed that different protocol such as e.g. seahorse mito stress test would provide a second line of evidence, and this must be considered in future studies.

Regarding phagocytosis, although increased ROS production and impaired phagocytic capacity of leukocytes is well described in traumatic brain injury (Liao et al. 2013) and spinal cord injury (Kanyilmaz et al. 2013), no changes were observed. Infectious complications e.g. pneumonia or ARDS seem to be associated with diminished neutrophilic phagocytosis and bacterial killing efficiency, with markedly higher decrease in trauma patients with ARDS compared with those with pneumonia and control (Mascellino et al. 2001). Whereas we have exposed isolated neutrophils from HV to sera obtained from traumatized patients, others have used isolated neutrophils from traumatized patients, which could explain such data differences. Furthermore, we did not stratify the patients according to their injury pattern, and thus, patients with several types of injuries including abdominal, head, extremities as well as thoracic traumata were included. Although it has been shown that phagocytosis of opsonized yeast by neutrophils reduced the expression of CXCR1 and CXCR2 (Doroshenko et al. 2002), we could not provide evidence for CXCR1 or CXCR2 involvement in phagocytosis in this experimental setting. A time-dependency of the observed effects as well as certain types of traumatic injuries to elaborate neutrophilic phagocytosis should be considered in larger studies.

CC16 protects lungs from cigarette smoke-induced injury by reducing NF-kappaB activation and alveolar cell apoptosis (Laucho-Contreras et al. 2015). Thus, CC16 can potentially prolong or shorten the longevity of neutrophils. However, it remains unclear, why there were no differences in apoptosis, since it is evident that inflammatory signals released after trauma do modulate apoptosis. The small sample size may explain why no differences were observed. It was shown that IL-1 $\beta$, TNF- $\alpha$, IL- 6 or IFN- $\gamma$ or bacterial products can interfere the physiologic process of apoptosis, and prolong the survival of PMNL after trauma (Colotta et al. 1992; Nolan et al. 2000). Moreover, in mechanically ventilated patients with ARDS, accelerated neutrophil apoptosis facilitated the resolution of inflammation in the preclinical models of lung inflammation. Taking together, the abnormal functions of neutrophils during severe trauma may cause a state of neutrophil paralysis (Phillipson and Kubes 2011; Alves-Filho et al. 2010) resulting in injury of host tissues (Phillipson and Kubes 2011). With regard to a potential mechanism, through upregulating the p53CXCR2 axis, CXCR2 could reinforce the cellular senescence of cancer cells caused by resveratrol-induced replication and oxidative stress, and this inhibited apoptosis ( $\mathrm{Li}$ et al. 2017). Our data show that CC16 modulated apoptosis of $\mathrm{CD} 6^{+}$granulocytes after neutralization of CXCR1 or CXCR2. Interestingly, the specific subsets of mature and hypersegmented, immunosuppressive cells after severe traumatic injury could reveal the influence of CC16 on their apoptosis rates via CXCR.

The expression of surface markers such as e.g. CXCR4 or CD62L can distinguish between the different neutrophil subsets (Pillay et al. 2012; Martin et al. 2003). As neutrophils age, they up-regulate cell surface expression of CXCR4 and acquire the ability to migrate towards CXCL12 (Nagase et al. 2002; Martin et al. 2003). Interestingly although apoptotic neutrophils still have a high expression of CXCR4, they cannot migrate to CXCL12 (Whyte et al. 1993). Thus, it can be differed between preapoptotic or "senescent" neutrophils and functionally and phenotypically distinct from apoptotic neutrophils, both expressing CXCR4 (Rankin 2010). Concomitant with CXCR4 up-regulation on ageing neutrophils, there is a decrease of the cell surface CXCR2 receptor expression, 
which itself plays an important role play in the recruitment of neutrophils to sites of inflammation, suggesting that senescent neutrophils have a reduced capacity for migration to these sites (Martin et al. 2003; Rankin 2010). With regard to the role of those cells in diseases, it was shown that neutrophils present in the synovial fluid of patients with inflammatory joint diseases and in the bronchoalveolar fluid of patients with chronic airways disease expressed high levels of CXCR4 (Bruhl et al. 2001; Hartl et al. 2008). Possibly, these cells age at this site of inflammation and do not re-enter the circulation for clearance. Here, we provide evidence for different responsiveness of the various neutrophil subsets to $\mathrm{CC} 16$ stimulation although for the phenotyping CD62L and not CXCR4 was applied. Tak et al. found that $\mathrm{CD} 62 \mathrm{~L}^{\mathrm{dim}}$ human neutrophils could be also seen as a separate aged subpopulation during inflammation (Tak and Firestein 2001). They show that banded neutrophils appeared much earlier in blood than CD62 $\mathrm{L}^{\mathrm{dim}}$ and segmented neutrophils (Tak et al. 2017). In healthy volunteers administrated with endotoxin or severe trauma patients, a subpopulation of $\mathrm{CD} 16^{\text {high }} \mathrm{CD} 62 \mathrm{~L}^{\text {low }}$ aged immunosuppressive neutrophils can be separated from whole human blood which was characterize by hypersegmented nuclei, a sign of aging change (SilvestreRoig et al. 2019; Pillay et al. 2012). We also report that anti-inflammatory $\mathrm{CC} 16$ can induce functional alterations of this $\mathrm{CD} 16^{\text {high }} \mathrm{CD} 62 \mathrm{~L}^{\text {low }}$ phenotype. It remains to be further studied in traumatic setting, if CD62L ${ }^{\text {dim }}$ cells are a truly separate subset that is recruited to the bloodstream in response to acute inflammation as suggested before (Tak et al. 2017). The depletion of the microbiota reduced the number of circulating aged neutrophils and dramatically improved the pathogenesis and inflammation-related organ damage in models of sickle cell disease or endotoxin-induced septic shock (Zhang et al. 2015). Thus, although neutrophils have been generally considered as a relatively homogeneous population for several decades, evidence for their true heterogeneity is emerging. This is also supported by differential impact of $\mathrm{CC} 16$ on the three subsets. As causative factors for their functional alterations their natural process of ageing and the replenishment by newly released neutrophils from the bone marrow, but also several other factors including e.g. genetics or microbiome are discussed.

Since in previous clinical study by Wutzler et al. it was shown that CC16 was a biomarker for detecting secondary respiratory complications in patients with multiple injuries (Wutzler et al. 2012), here, CC16 was not measured in the samples. Thus, this remains a limitation of the study, and it must be considered that $\mathrm{CC} 16$ values were not determined in the used samples. As a further limitation of the study, it remains to be considered that smoking, which is well-known to reduce CC16 levels was not documented. With this regard, several clinical studies have demonstrated that lower serum concentration of $\mathrm{CC} 16$ has been associated with the presence, risk, and progression of common obstructive lung diseases like asthma, COPD and smoking-related decline in lung function (Lam et al. 2018; Stenberg et al. 2018). The long-term Tucson Epidemiological Study of Airway Obstructive Diseases (TESAOD) further indicated that low serum concentration of $\mathrm{CC} 16$ was strongly associated with the mortality caused by cigarette smoke-related cancers, particularly lung cancer (Guerra et al. 2013). CC16 deficiency increases smoke-induced lung pathologies by its effects on epithelial cells, leukocytes, and fibroblasts in vivo (Laucho-Contreras et al. 2015). Interestingly, an experimental augmentation of CC16 levels in epithelial cells or smoke-exposed murine airways reduces inflammation and cellular injury (Pang et al. 2015; Pang et al. 2018). Thus, CC16 may play an important protective role in cigarette smoke-related diseases. Since we were unable to provide any information on the smoking behavior of included patients, we this remains a critical limitation of the present work and should be considered in future analyses.

\section{Conclusions}

In general, these results confirm previous studies regarding the anti-inflammatory potential of CC16. However, several new issues about the effects of CC16 on PMNL such as potentially CXCR1- or CXCR2-mediated oxidative burst and/or apoptosis by CC16 in certain neutrophil subsets have been provided. Summarized, the apparently CC16 migration-reducing and oxidative stress-inducing effects on PMNL may be associated with the development of post-traumatic pneumonia. On the one hand, an impaired ability of neutrophils to eliminate pathogens but also pathogen-associated molecular patterns, and on the other hand increased injury to the local tissues enhancing the susceptibility to infections e.g. in the lungs are possible. However, these anti-inflammatory effects may also play a protective role under inflammatory conditions, preventing an exaggerated local immune response and exceeding infiltration of e.g. lungs with PMN. This remains to be elucidated in further studies.

\section{Abbreviations}

APC: Allophycocyanin; ARDS: Acute respiratory distress syndrome; CC16: Club Cell protein 16; CD: Cluster of differentiation; ctrl: control; CXCR: CXC

chemokine receptors; ED: Emergency department; FACS: Fluorescence activated cell sorting; FITC: Fluorescein isothiocyanate; fMLP: N-formylmethionyl-leucyl-phenylalanin; HV: Healthy volunteers; IL: Interleukin; ISS: Injury severity score; MFU: Mean fluorescence units; MOF: Multiple organ failure; P: Pneumonia; PE: Phycoerythrin; PMNL: Polymorphonuclear leukocytes; ROS: Reactive oxygen species; SEM: Standard error of the mean; TNF: Tumor necrosis factor; TP: Trauma patients 


\section{Acknowledgements}

We thank Kerstin Kontradowitz and Katrin Jurida for outstanding technical assistance. We thank the DFG for funding the present work in part by DFG WU 820/2-1, HI 820/5-1, and RE 3304/8-1.

Parts of this study have been published as meeting abstracts.

\section{Authors' contributions}

BR designed the work. BR, SW and FH obtained the funding for the project. $B X$ and $A J$ performed the experiments. BX, AJ, LM, SE and BR substantially contributed to the conception and interpretation of data. BX, AJ, BR performed the analysis of data. BX and BR evaluated the data and drafted the manuscript. AJ, PS, JTV, and IM revised the manuscript critically for important intellectual content. SE contributed significantly to the interpretation of data and revised critically the manuscript for important intellectual content. All authors read and approved the final manuscript.

\section{Funding}

This study has been funded in part by DFG WU 820/2-1, HI 820/5-1, and RE 3304/8-1.

\section{Availability of data and materials}

A truncated data set used and/or analysed during the current study is available from the corresponding author on reasonable request.

\section{Ethics approval and consent to participate}

The study was performed in the University Hospital Frankfurt, Goethe University, Germany, with the institutional ethical committee approval in accordance with the Declaration of Helsinki following STROBE-guidelines. All healthy volunteers as well as patients that were included or their legally authorized representative signed the written informed consent form.

\section{Consent for publication}

Not applicable. The manuscript does not contain any individual persons data.

\section{Competing interests}

The authors declare that they have no competing interests.

\section{Author details}

'Department of Trauma, Hand and Reconstructive Surgery, University Hospital Frankfurt, Goethe University, Frankfurt, Germany. ${ }^{2}$ Department of Radiology and Nuclear Medicine, Experimental Radiology, Otto von Guericke University Magdeburg, Magdeburg, Germany. ${ }^{3}$ Department of Intensive and Intermediate Care, Medical Faculty, RWTH Aachen University, Aachen, Germany. ${ }^{4}$ Department of Trauma, Hand and Orthopedic Surgery, Helios Horst Schmidt Clinic, Wiesbaden, Germany. ${ }^{5}$ Department of Orthopaedic Trauma, University Clinic RWTH Aachen, Aachen, Germany. ${ }^{6}$ Department of Trauma and Reconstructive Surgery, Siegfried Weller Research Institute, Eberhard Karls University Tuebingen, BG Trauma Center Tuebingen, Tuebingen, Germany.

\section{Received: 19 April 2019 Accepted: 16 October 2019}

\section{Published online: 30 October 2019}

\section{References}

Alves-Filho JC, Spiller F, Cunha FQ. Neutrophil paralysis in sepsis. Shock. 2010; 34(Suppl 1):15-21.

Bahra P, Rainger GE, Wautier JL, Nguyet-Thin L, Nash GB. Each step during transendothelial migration of flowing neutrophils is regulated by the stimulatory concentration of tumour necrosis factor-alpha. Cell Adhes Commun. 1998;6(6):491-501.

Bernard A, Lauwerys R. Low-molecular-weight proteins as markers of organ toxicity with special reference to Clara cell protein. Toxicol Lett. 1995;77(1-3): $145-51$.

Bhatia RK, Pallister I, Dent C, Jones SA, Topley N. Enhanced neutrophil migratory activity following major blunt trauma. Injury. 2005;36(8):956-62.

Bruhl H, Wagner K, Kellner H, Schattenkirchner M, Schlondorff D, Mack M. Surface expression of CC- and CXC-chemokine receptors on leucocyte subsets in inflammatory joint diseases. Clin Exp Immunol. 2001;126(3):551-9.
Chishti AD, Shenton BK, Kirby JA, Baudouin SV. Neutrophil chemotaxis and receptor expression in clinical septic shock. Intensive Care Med. 2004;30(4): 605-11.

Colotta F, Re F, Polentarutti N, Sozzani S, Mantovani A. Modulation of granulocyte survival and programmed cell death by cytokines and bacterial products. Blood. 1992;80(8):2012-20.

Cote O, Clark ME, Viel L, Labbe G, Seah SY, Khan MA, et al. Secretoglobin 1A1 and $1 \mathrm{~A} 1 \mathrm{~A}$ differentially regulate neutrophil reactive oxygen species production, phagocytosis and extracellular trap formation. PLoS One. 2014; 9(4):e96217.

Donnelly SC, Haslett C, Dransfield I, Robertson CE, Carter DC, Ross JA, et al. Role of selectins in development of adult respiratory distress syndrome. Lancet. 1994;344(8917):215-9.

Doroshenko T, Chaly Y, Savitskiy V, Maslakova O, Portyanko A, Gorudko I, et al. Phagocytosing neutrophils down-regulate the expression of chemokine receptors CXCR1 and CXCR2. Blood. 2002;100(7):2668-71.

Eigenbrod T, Park JH, Harder J, Iwakura Y, Nunez G. Cutting edge: critical role for mesothelial cells in necrosis-induced inflammation through the recognition of IL-1 alpha released from dying cells. J Immunol. 2008;181(12):8194-8.

Gaudet RG, Sintsova A, Buckwalter CM, Leung N, Cochrane A, Li J, et al. INNATE IMMUNITY. Cytosolic detection of the bacterial metabolite HBP activates TIFA-dependent innate immunity. Science. 2015;348(6240):1251-5.

Giannoudis PV, Smith RM, Perry SL, Windsor AJ, Dickson RA, Bellamy MC. Immediate IL-10 expression following major orthopaedic trauma: relationship to anti-inflammatory response and subsequent development of sepsis. Intensive Care Med. 2000;26(8):1076-81.

Guerra S, Vasquez MM, Spangenberg A, Halonen M, Martinez FD. Serum concentrations of club cell secretory protein (Clara) and cancer mortality in adults: a population-based, prospective cohort study. Lancet Respir Med. 2013;1(10):779-85.

Guo RF, Sun L, Gao H, Shi KX, Rittirsch D, Sarma VJ, et al. In vivo regulation of neutrophil apoptosis by C5a during sepsis. J Leukoc Biol. 2006;80(6):1575-83.

Hartl D, Krauss-Etschmann S, Koller B, Hordijk PL, Kuijpers TW, Hoffmann F, et al. Infiltrated neutrophils acquire novel chemokine receptor expression and chemokine responsiveness in chronic inflammatory lung diseases. J Immunol. 2008;181(11):8053-67.

Hauser CJ, Otterbein LE. Danger signals from mitochondrial DAMPS in trauma and post-injury sepsis. Eur J Trauma Emerg Surg. 2018;44(3):317-24.

Hazeldine J, Hampson P, Lord JM. The impact of trauma on neutrophil function. Injury. 2014;45(12):1824-33.

Johansson S, Andersson K, Wennergren G, Wenneras C, Rudin A. CC16 inhibits the migration of eosinophils towards the formyl peptide fMLF but not towards PGD2. Inflammation. 2009;32(2):65-9.

Kanyilmaz S, Hepguler S, Atamaz FC, Gokmen NM, Ardeniz O, Sin A. Phagocytic and oxidative burst activity of neutrophils in patients with spinal cord injury. Arch Phys Med Rehabil. 2013;94(2):369-74.

Kikuchi-Ueda T, Tansho S, Ono Y. Enhancement of interleukin-8-induced chemotactic response and reactive oxygen species production in $\mathrm{HL}-60$ cells expressing CXCR1. J Infect Chemother. 2012;18(3):283-7.

Komaromy L, Tigyi A. A unique cell type in the lung--the Clara cell (the nonciliated bronchiolar epithelial cell). Acta Biol Hung. 1988;39(1):17-29.

Lam DC, Kwok HH, Yu WC, Ko FW, Tam CY, Lau AC, et al. CC16 levels correlate with cigarette smoke exposure in bronchial epithelial cells and with lung function decline in smokers. BMC Pulm Med. 2018;18(1):47.

Laucho-Contreras ME, Polverino F, Gupta K, Taylor KL, Kelly E, Pinto-Plata V, et al. Protective role for club cell secretory protein-16 (CC16) in the development of COPD. Eur Respir J. 2015;45(6):1544-56.

Li B, Hou D, Guo H, Zhou H, Zhang S, Xu X, et al. Resveratrol sequentially induces replication and oxidative stresses to drive p53-CXCR2 mediated cellular senescence in cancer cells. Sci Rep. 2017;7(1):208.

Liao Y, Liu P, Guo F, Zhang ZY, Zhang Z. Oxidative burst of circulating neutrophils following traumatic brain injury in human. PLoS One. 2013;8(7): e68963.

Liodaki E, Kalousis K, Mauss KL, Kisch T, Mailaender P, Stang F. Epidemiology of pneumonia in a burn care unit: the influence of inhalation trauma on pneumonia and of pneumonia on burn mortality. Ann Burns Fire Disasters. 2015;28(2):128-33.

Martin C, Burdon PC, Bridger G, Gutierrez-Ramos JC, Williams TJ, Rankin SM Chemokines acting via CXCR2 and CXCR4 control the release of neutrophils from the bone marrow and their return following senescence. Immunity. 2003;19(4):583-93. 
Martines RT, Araujo WG, Rodrigues $\mathrm{CL}$, Armond JE. Incidence of pedestrian traffic injury in Sao Paulo, Brazil, in 2016. Acta Ortop Bras. 2018;26(2):112-6.

Mascellino MT, Delogu G, Pelaia MR, Ponzo R, Parrinello R, Giardina A. Reduced bactericidal activity against Staphylococcus aureus and Pseudomonas aeruginosa of blood neutrophils from patients with early adult respiratory distress syndrome. J Med Microbiol. 2001;50(1):49-54.

Mittal M, Siddiqui MR, Tran K, Reddy SP, Malik AB. Reactive oxygen species in inflammation and tissue injury. Antioxid Redox Signal. 2014;20(7):1126-67.

Nagase H, Miyamasu M, Yamaguchi M, Imanishi M, Tsuno NH, Matsushima K, et al. Cytokine-mediated regulation of CXCR4 expression in human neutrophils. J Leukoc Biol. 2002;71(4):711-7.

Nam KW, Kim TJ, Lee JS, Kwon HM, Lee YS, Ko SB, et al. High neutrophil-tolymphocyte ratio predicts stroke-associated pneumonia. Stroke. 2018;49(8): 1886-92.

Negrin LL, Halat G, Kettner S, Gregori M, Ristl R, Hajdu S, et al. Club cell protein 16 and cytokeratin fragment 21-1 as early predictors of pulmonary complications in polytraumatized patients with severe chest trauma. PLoS One. 2017;12(4):e0175303.

Nolan B, Collette H, Baker S, Duffy A, De M, Miller C, et al. Inhibition of neutrophil apoptosis after severe trauma is NFkappabeta dependent. J Trauma. 2000; 48(4):599-604 discussion -5.

Pallister I, Dent C, Topley N. Increased neutrophil migratory activity after major trauma: a factor in the etiology of acute respiratory distress syndrome? Crit Care Med. 2002;30(8):1717-21.

Palmer CS, Lang J, Russell G, Dallow N, Harvey K, Gabbe B, et al. Mapping abbreviated injury scale data from 1990 to 1998 versions: a stepping-stone in the contemporary evaluation of trauma. Injury. 2013:44(11):1437-42.

Pang M, Liu HY, Li T, Wang D, Hu XY, Zhang XR, et al. Recombinant club cell protein 16 (CC16) ameliorates cigarette smokeinduced lung inflammation in a murine disease model of COPD. Mol Med Rep. 2018;18(2):2198-206.

Pang M, Wang H, Bai JZ, Cao D, Jiang Y, Zhang C, et al. Recombinant rat CC16 protein inhibits LPS-induced MMP-9 expression via NF-kappaB pathway in rat tracheal epithelial cells. Exp Biol Med. 2015;240(10):1266-78.

Pang M, Yuan Y, Wang D, Li T, Wang D, Shi X, et al. Recombinant CC16 protein inhibits the production of pro-inflammatory cytokines via NF-kappaB and p38 MAPK pathways in LPS-activated RAW264.7 macrophages. Acta Biochim Biophys Sin. 2017:49(5):435-43

Phillipson M, Kubes P. The neutrophil in vascular inflammation. Nat Med. 2011; 17(11):1381-90

Pillay J, Kamp VM, van Hoffen E, Visser T, Tak T, Lammers JW, et al. A subset of neutrophils in human systemic inflammation inhibits $T$ cell responses through mac-1. J Clin Invest. 2012;122(1):327-36.

Rainer TH, Lam NY, Chan TY, Cocks RA. Early role of neutrophil L-selectin in posttraumatic acute lung injury. Crit Care Med. 2000;28(8):2766-72.

Rankin SM. The bone marrow: a site of neutrophil clearance. J Leukoc Biol. 2010; 88(2):241-51.

Relja B, Henrich D, Wetzel G, Sander AL, Jakob H, Maraslioglu M, et al. Effects of acute ethanol gavage on intestinal integrity after hemorrhage/resuscitation. Scand J Gastroenterol. 2013;48(4):448-58.

Relja B, Taraki R, Teuben MP, Mors K, Wagner N, Wutzler S, et al. Sera from severe trauma patients with pneumonia and without infectious complications have differential effects on neutrophil biology. BMC Pulm Med. 2016;16(1):171.

Rivkind Al, Siegel JH, Littleton M, De Gaetano A, Mamantov T, Laghi F, et al. Neutrophil oxidative burst activation and the pattern of respiratory physiologic abnormalities in the fulminant post-traumatic adult respiratory distress syndrome. Circ Shock. 1991;33(1):48-62.

Rosales C, Demaurex N, Lowell CA, Uribe-Querol E. Neutrophils: their role in innate and adaptive immunity. J Immunol Res. 2016;2016:1469780

Rzeniewicz K, Newe A, Rey Gallardo A, Davies J, Holt MR, Patel A, et al. L-selectin shedding is activated specifically within transmigrating pseudopods of monocytes to regulate cell polarity in vitro. Proc Natl Acad Sci U S A. 2015; 112(12):E1461-70

Sadeghi-Bazargani H, Samadirad B, Shahedifar N, Golestani M. Epidemiology of road traffic injury fatalities among Car users; a study based on forensic medicine data in East Azerbaijan of Iran. Bull Emerg Trauma. 2018;6(2):146-54.

Sakamaki F, Ishizaka A, Handa M, Fujishima S, Urano T, Sayama K, et al. Soluble form of P-selectin in plasma is elevated in acute lung injury. Am J Respir Crit Care Med. 1995;151(6):1821-6.

Scaffidi P, Misteli T, Bianchi ME. Release of chromatin protein HMGB1 by necrotic cells triggers inflammation. Nature. 2002;418(6894):191-5.
Schrama AJ, Elferink JG, Hack CE, de Beaufort AJ, Berger HM, Walther FJ. Pulmonary secretory phospholipase A2 in infants with respiratory distress syndrome stimulates in vitro neutrophil migration. Neonatology. 2010; 97(1):1-9.

Shen XF, Cao K, Jiang JP, Guan WX, Du JF. Neutrophil dysregulation during sepsis: an overview and update. J Cell Mol Med. 2017;21(9):1687-97.

Silvestre-Roig C, Fridlender ZG, Glogauer M, Scapini P. Neutrophil diversity in health and disease. Trends Immunol. 2019;40(7):565-83.

Stenberg H, Wadelius E, Moitra S, Aberg I, Ankerst J, Diamant Z, et al. Club cell protein (CC16) in plasma, bronchial brushes, BAL and urine following an inhaled allergen challenge in allergic asthmatics. Biomarkers. 2018; 23(1):51-60.

Sturm R, Heftrig D, Mors K, Wagner N, Kontradowitz K, Jurida K, et al. Phagocytizing activity of PMN from severe trauma patients in different posttraumatic phases during the 10-days post-injury course. Immunobiology 2017;222(2):301-307.

Tak PP, Firestein GS. NF-kappaB: a key role in inflammatory diseases. J Clin Invest. 2001;107(1):7-11

Tak T, Wijten P, Heeres M, Pickkers P, Scholten A, Heck AJR, et al. Human CD62L(dim) neutrophils identified as a separate subset by proteome profiling and in vivo pulse-chase labeling. Blood. 2017;129(26):3476-85.

van den Berg CW, Tambourgi DV, Clark HW, Hoong SJ, Spiller OB, McGreal EP. Mechanism of neutrophil dysfunction: neutrophil serine proteases cleave and inactivate the C5a receptor. J Immunol. 2014;192(4):1787-95.

Wagner N, Dieteren S, Franz N, Kohler K, Mors K, Nicin L, et al. Ethyl pyruvate ameliorates hepatic injury following blunt chest trauma and hemorrhagic shock by reducing local inflammation, NF-kappaB activation and HMGB1 release. PLoS One. 2018;13(2):e0192171.

Wang L, Zhao XC, Cui W, Ma YQ, Ren HL, Zhou X, et al. Genetic and pharmacologic inhibition of the chemokine receptor CXCR2 prevents experimental hypertension and vascular dysfunction. Circulation. 2016; 134(18):1353-68.

Wang Y, Xu Y, Zhang P, Ruan W, Zhang L, Yuan S, et al. Smiglaside a ameliorates LPS-induced acute lung injury by modulating macrophage polarization via AMPK-PPARgamma pathway. Biochem Pharmacol. 2018.

Weaver KD, Branch CA, Hernandez L, Miller CH, Quattrocchi KB. Effect of leukocyte-endothelial adhesion antagonism on neutrophil migration and neurologic outcome after cortical trauma. J Trauma. 2000;48(6):1081-90.

Whyte MK, Meagher LC, MacDermot J, Haslett C. Impairment of function in aging neutrophils is associated with apoptosis. J Immunol. 1993;150(11):5124-34.

Winterbourn CC, Kettle AJ, Hampton MB. Reactive oxygen species and neutrophil function. Annu Rev Biochem. 2016;85:765-92.

Wutzler S, Backhaus L, Henrich D, Geiger E, Barker J, Marzi I, et al. Clara cell protein 16: a biomarker for detecting secondary respiratory complications in patients with multiple injuries. J Trauma Acute Care Surg. 2012;73(4):838-42.

Wutzler S, Lehnert T, Laurer H, Lehnert M, Becker M, Henrich D, et al. Circulating levels of Clara cell protein 16 but not surfactant protein D identify and quantify lung damage in patients with multiple injuries. J Trauma. 2011;71(2):E31-6.

Zhang D, Chen G, Manwani D, Mortha A, Xu C, Faith JJ, et al. Neutrophil ageing is regulated by the microbiome. Nature. 2015;525(7570):528-32.

Zhang Q, Itagaki K, Hauser CJ. Mitochondrial DNA is released by shock and activates neutrophils via p38 map kinase. Shock. 2010b;34(1):55-9.

Zhang Q, Raoof M, Chen Y, Sumi Y, Sursal T, Junger W, et al. Circulating mitochondrial DAMPs cause inflammatory responses to injury. Nature. 2010a; 464(7285):104-7.

\section{Publisher's Note}

Springer Nature remains neutral with regard to jurisdictional claims in published maps and institutional affiliations. 